\title{
CONGENITAL ARTERIO-VENOUS ANEURYSM OF THE RETINA*
}

\author{
BY \\ MALCOLM E. CAMERON \\ Brisbane, Australia
}

THE first case of arterio-venous aneurysm of the retina to be described was that of Magnus (1874), and since that time not more than forty cases have been reported in the literature. They form an intensely interesting series of cases, and it is the purpose of this paper to discuss their signs and symptoms and to present one additional case with fundus drawing and angiographic evidence of an accompanying intracerebral angioma.

\section{Fundus Picture}

The fundus picture differs according to the number of vessels involved. The disc may be wholly obscured by a mass of tortuous and twisting blood vessels, which represent several arteries and veins that have emerged from the disc and become inextricably wound around each other (Biro, 1951). Here, arteries and veins are difficult to distinguish from each other either by colour or size, and no vessel can be followed for more than a very short distance, as it soon disappears into a mass of convolutions. The macula may be completely covered by vessels, but further out the size and complexity of the vessels decrease although they still remain more tortuous than normal.

In other cases, only one or two vessels are affected, the remaining vessels being normal, and it is in these cases that the vessels can be more intimately studied. Often the three varieties of arterio-venous aneurysm are represented in one fundus. The most striking and common presentation is that in which the large convoluted artery and vein join each other at the end of their course without any intervening capillary bed. The artery is generally the same size as the vein, although both are grossly increased in diameter (from two to ten times). The colour of the blood may be the same as in normal vessels, the actual point of transition between arterial and venous blood being well seen. The transition point is not abrupt but extends over one or two disc lengths of vessel. In this transition area the blood colour is that of a mixture of arterial and venous blood.

In other vessels the blood colour represents a mixture of arterial and venous blood, and they can be classified neither as arteries nor as veins. The vessel walls are often increased in thickness as is shown by sheathing. This is intermittent and quite pronounced in places, and is sometimes seen on

* Received for publication January 21, 1958. 
only one side of the vessel wall. In the case described below only one vein was sheathed.

The second type of arterio-venous aneurysm is the angioma. This consists of an oval mass of small vessels supplied by an artery and usually drained by several small veins, the whole being often less than the disc in size. An angioma is seen in Seidel's case just below the disc. The angioma is not to be confused with the haemangioblastoma of the von Hippel-Lindau syndrome, which is a mass of actively proliferating angioblastic tissue.

The third type is that in which an artery and vein are joined by an anomalous vessel. This is well seen in the present case, where the right superior nasal vein and a right inferior nasal artery are joined by a vertically running vessel. Here the artery and vein were of normal appearance, and after being joined by the anomalous vessel, they continued their course uneventfully to the periphery of the retina. Again the interface between the arterial and venous blood columns in the middle of the anomalous vessel can be seen.

The cause of the condition is probably congenital. The earliest age at which it has been seen is 8 years (Schleich; reported by Rundles and Falls, 1951), and three have been described at 9 years, including the author's case.

The absence of capillaries is a persistence of that type of vascular system found in the eye of a 4-mth (110-mm.) human embryo (Michaelson, 1948). Here the vascular system is represented by an undifferentiated primordium in which the four primary vessel complexes (upper and lower temporal, and upper and lower nasal) can be recognized. The capillaries are budded from the nipple-like protuberances of that part of the vein wall which lies remote from the artery, thus leaving the characteristic peri-arterial capillary-free area. The disturbance which brings about the anomalous middle cerebral vessels takes place at a much earlier stage of embryonic development and involves the anterior and middle vascular plexuses. These two plexuses overlie the mid-brain during their differentiation, and are cut off from the hyaloid system of vessels by closure of the optic stalk at the 12-mm. (5-week) stage. Wyburn-Mason (1943) has suggested that it is just at this time that a common disturbance could affect both the retinal and middle cerebral circulations, and bring about a tract of anomalous vascular tissue stretching from the retina to the mid-brain. However there is no retinal circulation at this time, and between the $12-\mathrm{mm}$. and $110-\mathrm{mm}$. stages the hyaloid system of vessels develops and subsequently regresses. The retinal vessels only develop at the $100-\mathrm{mm}$. stage as budding from the hyaloid artery at the disc; so that if there were a common disturbance, one would expect persistence or malformation of the hyaloid vessels. This has not been seen in association with a retinal arterio-venous aneurysm.

\section{Associated Features}

Visual Fields.-These are generally normal. When they are abnormal, the defect is an homonymous hemianopia, and in these cases an intracerebral 
angioma is also invariably present. The field loss is due to the interruption of the optic tract connexions by an angiomatous mass of vessels. This is well seen in Case 7 of Wyburn-Mason (1943), with a left retinal arteriovenous aneurysm. There was a right homonymous hemianopia, which at autopsy was found to be due to the penetration of the left optic tract by anomalous vessels.

Situation of Intracerebral Angioma.-The location of the angioma has been determined by Mackenzie (1953) in a series of fifty cases. The majority of the angiomata were located on either side of the Sylvian fissure, corresponding to their origin from the middle cerebral vessels, although there were others in the base of the brain and the frontal, temporal, parietal, and occipital lobes.

Size.-Half of the angiomata were described as large. The author's measured approximately $7 \times 4 \mathrm{~cm}$.

Hemiplegia.-A hemiplegia caused by a subarachnoid or intracerebral haemorrhage develops in a majority of those cases complicated by an intracerebral angioma. The hemiplegia may be sudden in onset, or more often its onset is gradual over a period of a few years. It may be due to small leaks, or to anaemia of the cerebral cortex supplied by the middle cerebral artery caused by the rapid shunting of blood from the arterial to the venous side. In any case the ultimate prognosis after a haemorrhage from an angioma is better than that after the more common berry aneurysm.

Other accompanying signs and symptoms include bruit, headache, epilepsy, speech defect, facial and oculomotor nerve paralysis including ptosis, conjugate paralysis, squint, hydrocephalus, angiomata of the skin and proptosis.

Pupillary Changes.-Unfortunately the reactions of the pupils are not mentioned in thirty of the 31 cases collected from the literature by Rundles and Falls (1951). In the case described by Biro (1951), the fields were normal with visual acuity in the affected eye $5 / 10$, and the pupillary reflexes were normal. In the author's case neither pupil reacted directly, consensually, or to accommodation, but the patient's right eye was blind and the left eye showed a temporal hemianopia although the visual acuity was $6 / 6$ partly. In most of the cases quoted by Wyburn-Mason (1943) there were pupillary abnormalities of size and reaction, and mid-brain angiomata were found in any such cases coming to autopsy.

Visual Acuity.-In 30 per cent. of cases the visual acuity is $6 / 9$ or better, and in the remainder it varies from $6 / 12$ to no perception of light.

To what is this decreased visual acuity due? In some cases at least it does not appear to be due to encroachment on the optic nerve fibres by the angiomatous vessels, as sometimes, where a large mass of vessels completely obscures the disc, the vision is normal, and in others in which the fundus shows only a few vessels affected there is no perception of light. 
It may be that, just as there is a failure in the differentiation of the primordial vascular system, there is also a failure in the development of the retinal elements. The rods and cones and their nuclei, the bipolar cells, and the ganglion cells all differentiate between the third and seventh months, and a defect involving any of these cells could be responsible for the decreased visual acuity.

However, in one of two histological examinations of a retina with arteriovenous aneurysm that have been carried out (Brock's Case 3, quoted by Wyburn-Mason), the dilated and tortuous retinal vessels were found to occupy the greater part of the thickness of the retina. The remaining small amount of retinal tissue was degenerate and cystic. Similarly the optic nerve was found to be occupied mainly by a tangle of blood vessels, very little if any conducting tissue being left. The other case (Krug and Samuels, quoted by Reese, 1951) showed essentially the same histological picture. In the author's case also, the right optic foramen was shown to be twice as big as the normal left optic foramen. This would indicate that, at least in this case, the absence of perception of light is due to the exclusion of the optic nerve fibres by the anomalous vessels.

The decrease in the nervous tissue of the retina caused by the angiomatous vessels would explain the poor visual acuity in cases in which arterio-venous aneurysms of the retina are numerous. It is, however, an unsatisfactory explanation in cases with only an occasional arterio-venous aneurysm and absence of perception of light, and it is in these cases that agenesis of the primordial retinal cells may play a part. Histological examination of such a retina will one day provide the answer.

Differential Diagnosis.-The only other condition in which an arteriovenous aneurysm appears is the von Hippel-Lindau syndrome. Here the retina is seen to contain (usually in the periphery) a haemangioblastoma which slowly grows and eventually destroys the eye. As the haemangioblastoma grows, the artery and vein feeding it become very tortuous and greatly increased in size. Exudates appear, the retina becomes grossly oedematous and detached, and secondary glaucoma supervenes. A hereditary nature is seen in about 20 per cent. of the cases, while a similar percentage is complicated by cerebellar, medullar, and spinal cord cysts. Arterio-venous aneurysm of the retina, on the other hand, is a stationary condition, no difference in the fundus appearance being seen after many years of observation. There is no hereditary incidence, and the complicating brain angiomata have almost all been supratentorial, mainly cerebral.

\section{Case Report}

The following case of retinal arterio-venous aneurysm illustrates many of the above points.

A single woman, born in September, 1933, came from a family of six children. There are three girls older and two boys younger than the patient, and all are well with no eye 
symptoms. The mother died of carcinoma of the right breast when the patient was 13 years of age. The father is alive but is a chronic alcoholic. The father and mother each came from a family of seven, none of whom suffers from any ocular abnormality. Two elder sisters are married, with one child each, and these children are normal.

The patient received a normal state school education until the age of 13 years, when she passed the qualifying examination to the secondary school quite creditably, obtaining 89 per cent. for Arithmetic and 67 per cent. for English. Thereafter she drifted to domestic work in cafés until the gradual onset of a left hemiplegia incapacitated her 3 years later.

The blindness in the right eye was discovered when she was 9 years of age, at a routine medical examination by the School Health Service, but its cause was not investigated. She first menstruated at the age of 16 years, while her three sisters began to menstruate at the age of 14 years, and since then she has menstruated only once every two years. She had frequent diarrhoea until one year ago, but has normal bowel action now. She has suffered all her life from nocturnal enuresis.

When she was 16 the left foot turned to the equinovarus

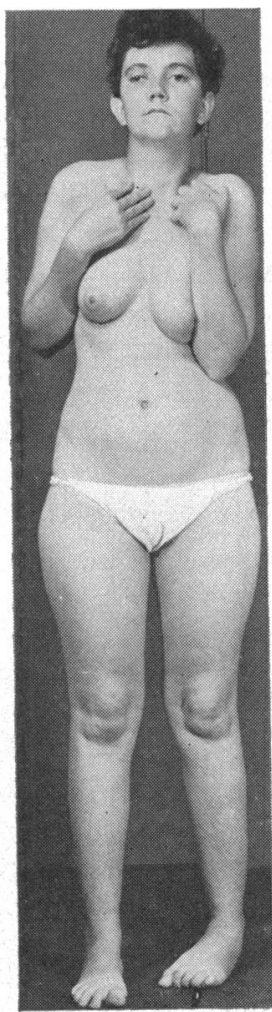

FIG. 1.-Left hemiplegia. position and she has since had to wear a leg iron with a toespring. A few months later her left arm and hand became weak, and she now holds them in the main d'accoucheur position.

Her headache began at the age of 17 years and is still present in a severe form. It is constantly present, worse in the right side of the head; it is described as "like a boil throbbing away all the time", and sounds "like a buzzing or surging noise". Because of the headache and the partial hemiplegia she was admitted to hospital, where she was diagnosed as suffering from hysteria.

A year later (at the age of 18), the left side of the face became suddenly weak, and she had difficulty swallowing coarse food such as apples or lettuce. Her voice became thick and her speech slow. An operation was done to correct a right convergent squint, but two weeks later the eye deviated outwards, where it has remained since. One year later she was given a course of radium therapy to the head, which had no demonstrable effect except to produce a partial alopecia.

By the time she was 21 the left hemiplegia and headache had become progressively worse, and she was admitted to hospital again for investigation. This time her true condition was recognized with the help of ventriculography and a left carotid arteriogram.

At no time did she suffer from migraine or epileptiform attacks, and the Wassermann, Kahn, and Kline reactions were negative.

Clinical Examination in July, 1957, at age 23 years.-She presented as a young woman looking older than her age, with a dull facial expression (Fig. 1). The speech was thick and slow, but the patient was quite intelligent and showed good insight. The left hand was held as a main d'accoucheur, and only gross clumsy movements were possible. The left leg was in the equinovarus position. A loud bruit was heard all over the head, but best in the right temporo-parietal region.

The lungs, heart (blood pressure $120 / 80 \mathrm{~mm}$. $\mathrm{Hg}$ ), abdomen, and secondary sex characteristics were normal.

The power in the left upper and lower limbs was less than in the right, but not greatly so. Tone, joint sense, and co-ordination were normal. There was no Rombergism, and no sensory loss to pinprick or touch. The jerks were all present and equal, except for the left knee and ankle jerks, which were a little brisker than the right. The right 
plantar reflex was flexor, and the left was variable. There was a left upper motor neuron facial paresis with weakness of the left masticatory muscles. She could not whistle or swallow coarse food easily. The corneal reflexes were present and equal. Nerves II, VIII, IX, X, XI, and XII were normal.

Eye Examination.-There was a partial right ptosis, and the right eye was divergent $45^{\circ}$ (Fig. 2). All the movements of the eyes were poor except abduction of the left eye.

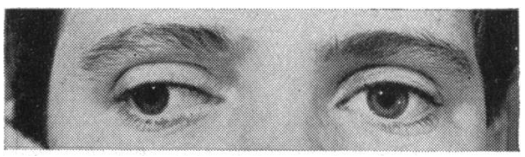

FIG. 2.-Right ptosis, left facial paralysis.

The pupils were equal, central, circular, and about $3 \mathrm{~mm}$. in diameter. They did not react to light directly or consensually or to accommodation. They dilated evenly with gutt. Neosynephrine 10 per cent. and gutt. homatropine and cocaine 2 per cent. of each. It was impossible, unfortunately, to test for Wernicke's hemianopic pupillary reaction.

The visual acuity in the right eye was no perception of light, and in the left $6 / 6$ partly, J2. The retinoscopic findings were normal, and the left vision could not be improved with glasses. The left central and peripheral fields showed a temporal hemianopia (Fig. 3). There was no papilloedema and no pulsation of the vessels in either fundus.

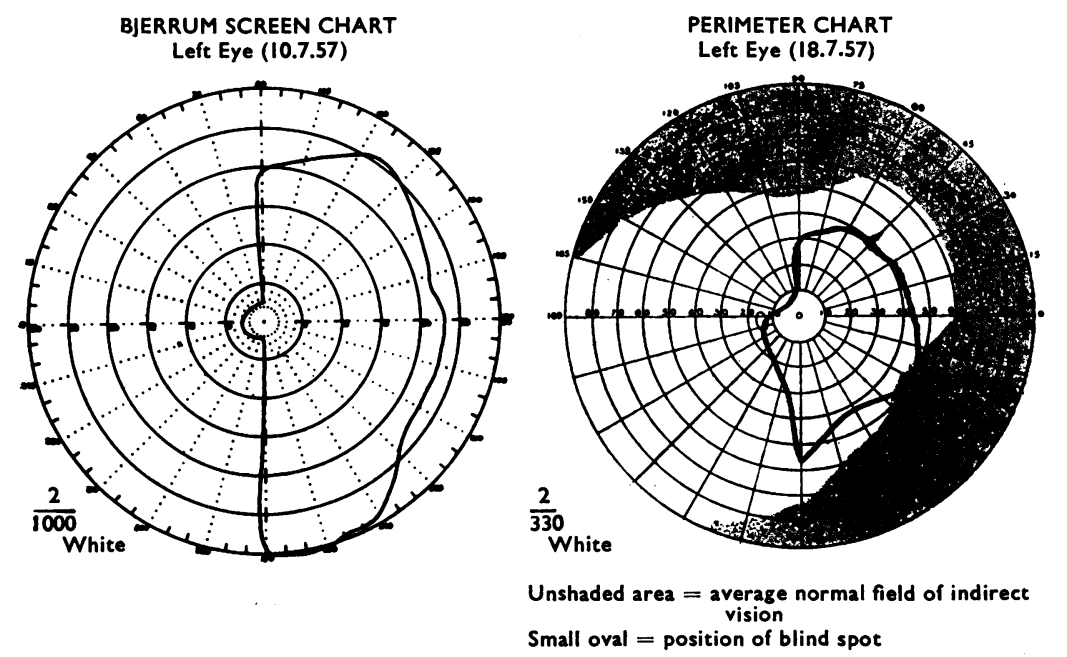

Fig. 3.-Left temporal hemianopia in a woman aged 23 years with visual acuity $6 / 6$ ptly.

The left media, disc, and vessels were normal. The right media and macula were normal, but the vessels emerging from the right disc showed an interesting abnormality (Fig. 4, opposite). At 12 o'clock on the disc, and directed upwards, emerge a large artery and vein, each about three times wider than normal. They each receive a tributary just above the disc, and after numerous convolutions join each other at the retinal periphery, their junction being indicated by a change in the colour of the contained blood.

At 6 o'clock on the right disc, a similar large artery and vein emerge, the vein dividing soon into two, the artery dividing a little further on. Both corresponding branches subsequently join each other at the periphery of the fundus, where again the colour change can be seen. 
Immediately below the disc, and attached to an artery, is a very small angioma with one afferent vein. Next to the artery is another, the normal arterial colour of which changes to that of mixed arterial-venous blood half way down.

Nasal to the disc can be seen an anomalous vessel joining the left superior nasal vein and a left superior nasal artery, and again there is a colour change midway along this vessel.

FIG. 4.-Right fundus.

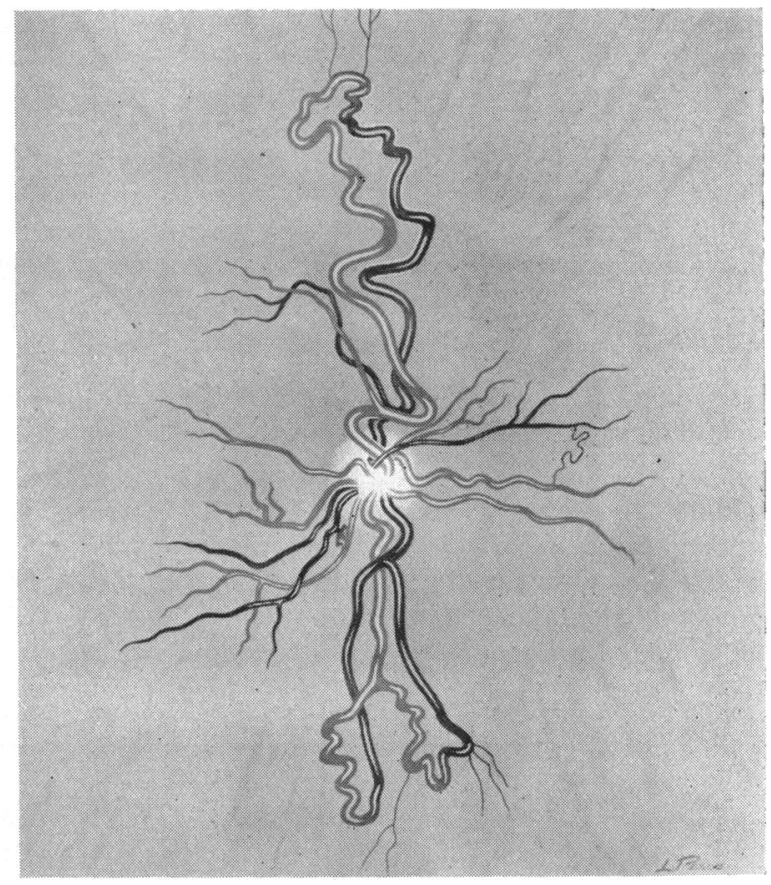

The abrupt change in colour between the arterial and venous blood columns is an interesting phenomenon which does not appear to have been commented on before, although it has most certainly been observed (Cashell, 1948). Clark (1938), observing the arterio-venous anastomoses normally present in a rabbit's ear by the transparent chamber technique, remarked that there was no change in the colour of the brick-red arterial blood in the anastomosis. However, he did not comment on its colour change when it reached the venule which was filled with venous blood derived from the distal capillary net. In the accompanying case there was practically no capillary net distal to the anastomosis. In fact, the only tributaries of the superior anomalous vessels were a small normal-looking artery and vein which came off just above the disc, and a few long and extremely thin vessels which came off near the junction of the artery and vein and disappeared into the ora.

The anatomical configuration does not therefore resemble those normal arterio-venous anastomoses in man which have been found in the penis, tips of the fingers, and bases of the nails. It resembles rather the condition obtaining in traumatic arterio-venous aneurysm (Callander, 1920). In traumatic arterio-venous aneurysm the proximal artery is often dilated and extremely tortuous, while the distal vein is distended and its media hypertrophied.

In the author's case the superior artery and vein are equal in size and about three times the diameter of a normal vein at the disc. The hypertrophy of the muscular coat of the vein is indicated by its sheathing, which is most prominent in the upper half of the vein, where the effect of the arterial pressure is greatest.

In traumatic arterio-venous aneurysm, the entering arterial blood dilates the vein by blocking the venous return as well as by subjecting it to increased pressure. In retinal 
arterio-venous aneurysm, only the latter effect operates, as the anastomoses are mainly end anastomoses. In this connexion it is interesting to observe Ney's measurements (quoted by Callander, 1920) of the arterial and venous pressures in experimental aneurysms in dogs. Ney found that the normal arterial and venous pressures were approximately 112 and $10 \mathrm{~mm}$. $\mathrm{Hg}$ respectively. After the fistulization the pressures in the proximal and distal portions of both artery and vein were the same, varying between 70 and 105 $\mathrm{mm}$. Hg. This supports the contention that the arterial and venous pressures are equal on either side of the junction of the blood columns, and helps to explain the precise nature of the interface. The arterial blood column cannot push back the venous column, and equilibrium is established at a pressure which is a little less than the normal arterial pressure but much greater than the normal venous pressure, the latter fact accounting for the venous dilation.

The arterial dilation is not so easy to explain, and many theories have been advanced to account for it. It may be that the dilation is due to a loss of tone, as is exemplified by the lower arterial pressure. The distal arterial tree is no longer fed by the artery, and consequently on being short circuited its pressure falls, and with the fall in pressure there is a reduction in tone.

\section{Radiological Examination}

Flat X-Ray Film.-Preliminary $x$-ray films of the skull show a small pituitary fossa with bridged clinoid processes (Fig. 5). There is no calcification to be seen. Surprisingly enough, the vascular shadows in the vertex of the skull appear normal, but there is an extremely large right sigmoid and transverse sinus and a large jugular foramen. No basal view was taken. No other abnormality is to be seen in the skull, and the pineal gland is not calcified. This fact did not permit any assessment of the shift in the plain films.

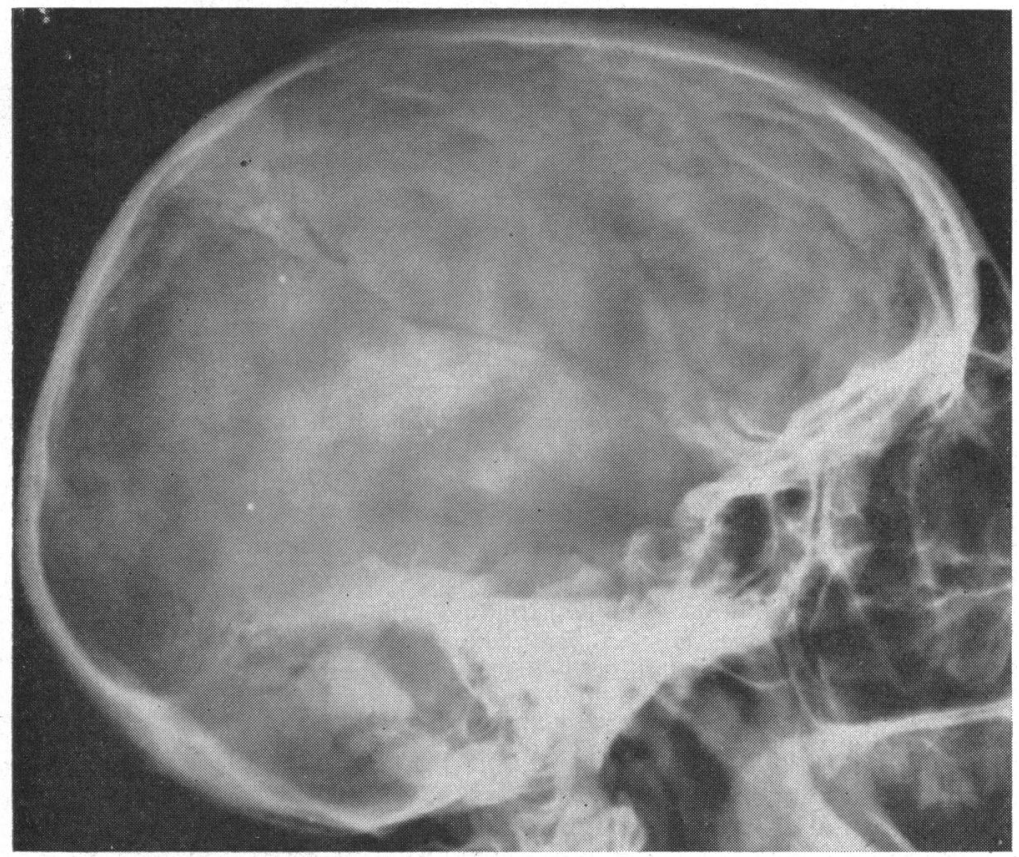

FIG. 5.-Flat $x$-ray of skull. 
$X$-Ray Appearance of the Optic Foramina.-The left optic foramen is normal in size. The right optic foramen is enlarged, being about twice the size of the left (Fig. 6).

Left Right

FIG. 6.-Optic foramina.

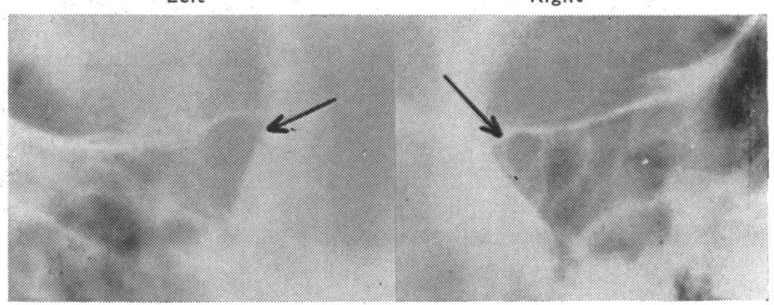

\section{Left Carotid Arteriogram}

ARTERIAL PHASE.- The lateral view shows a large vascular tumour at the base of the brain apparently arising from the middle cerebral vessel (Fig. 7).

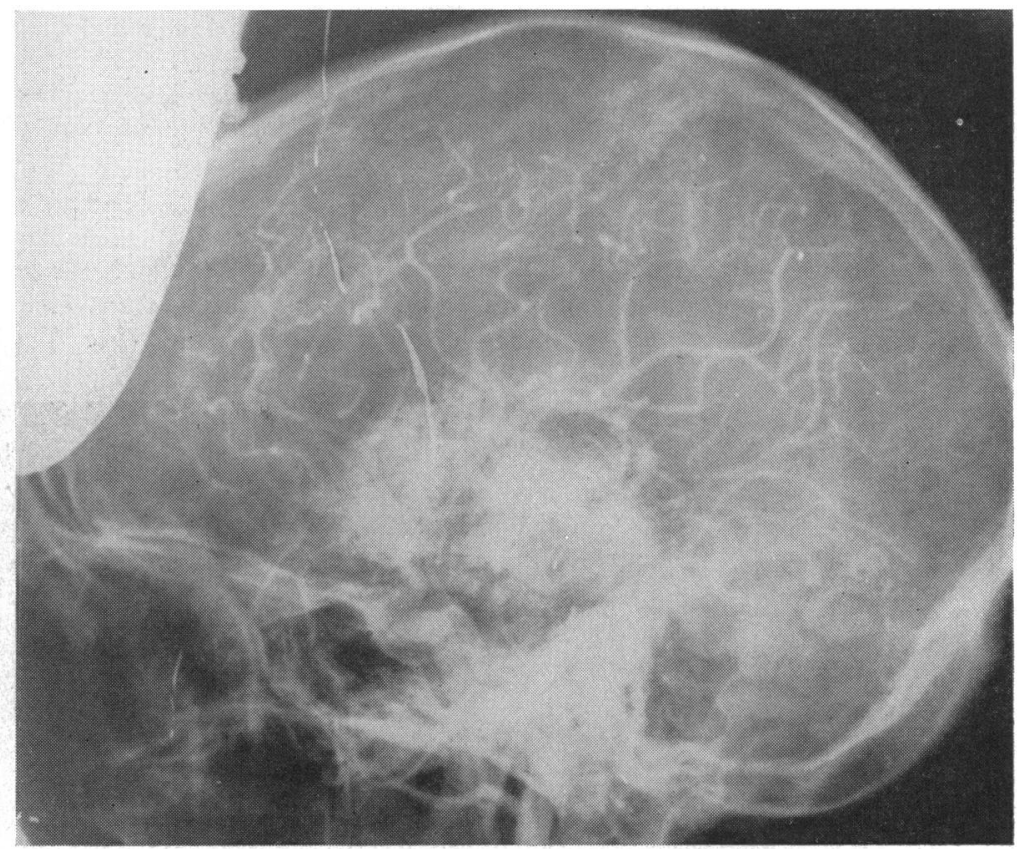

Fig. 7.-Arterial phase, lateral view.

It is roughly semicircular in shape in the lateral view, measuring $7 \times 4 \mathrm{~cm}$. The antero-posterior view shows that two-thirds of the tumour lie to the right of the midline, the remaining one-third lying to the left (Fig. 8, overleaf).

In the antero-posterior view the left anterior cerebral artery is well displaced laterally. The right anterior cerebral artery fills and is normal in position. . The left middle cerebral artery is displaced laterally, and it would appear that the angiomatous mass arises from the right middle cerebral artery.

CAPILLARY PHASE.-This shows intense opacification of the tumour with sizeable vessels and, very early in the piece, commencing venous drainage. 


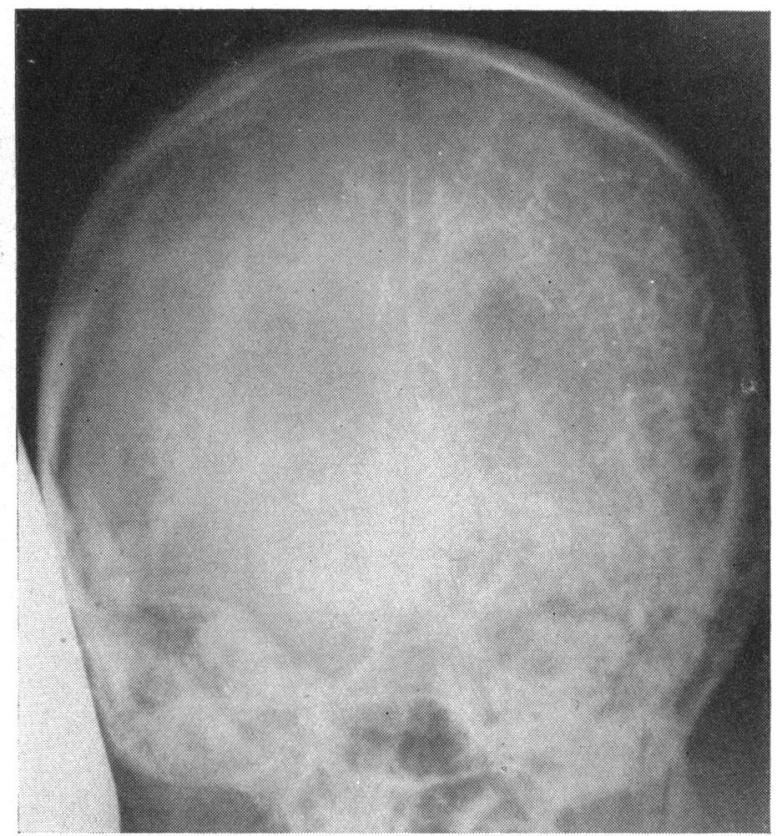

VENOUS PHASE.-The predominant drainage appears to be through the great vein of Galen, which is densely opacified, but the dye does not outline the transverse and sigmoid sinuses, probably because of the dilution of the dye at this stage (Fig. 9).

FiG. 9.-

Venous

phase,

lateral

view.

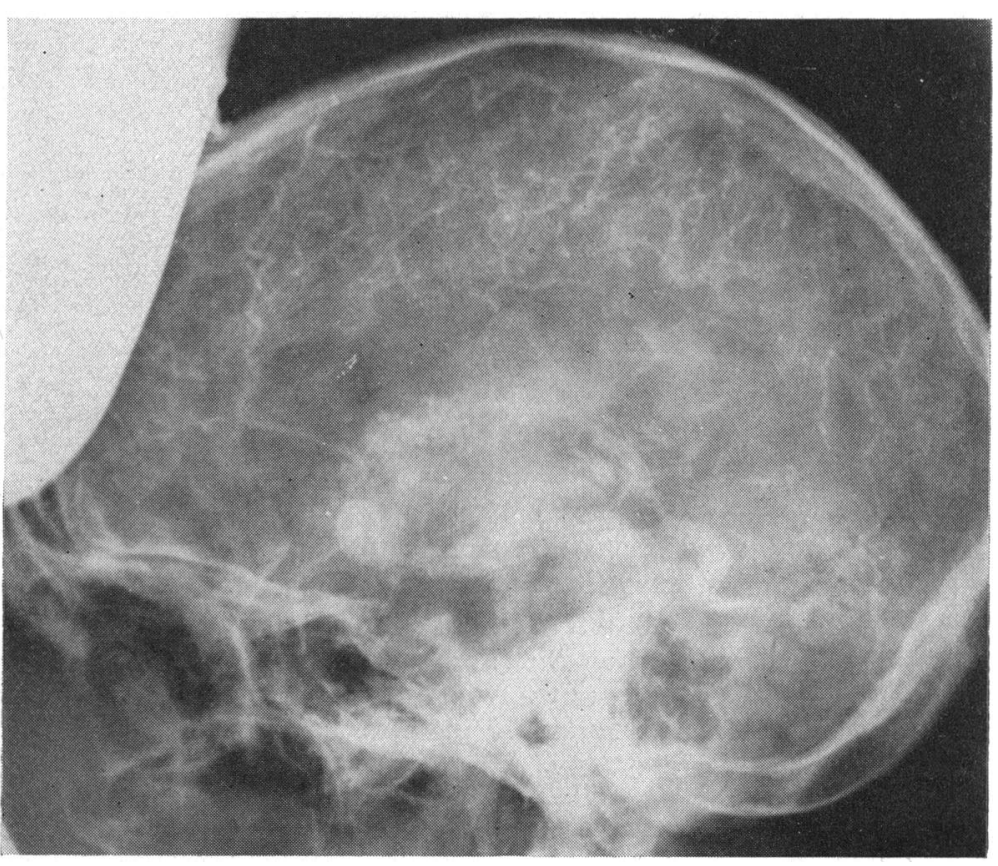


VENTRICULOGRAM.-This shows a general dilation of the lateral ventricles, the anterior, posterior, and temporal horns (Figs 10 and 11). Beneath this, but displaced upwards and backwards, is quite a large third ventricle, which is no doubt the site of a partial obstruction. There is no excess air over the surface of the hemispheres, which would suggest that the dilatation of the ventricles has not been produced by general atrophy, but rather by partial internal hydrocephalus due to pressure by the tumour. Also, although no good view has been obtained of the fourth ventricle, there is some basal air, which would indicate that the obstruction is certainly only partial.

Fig. 10.Ventriculogram, lateral view.
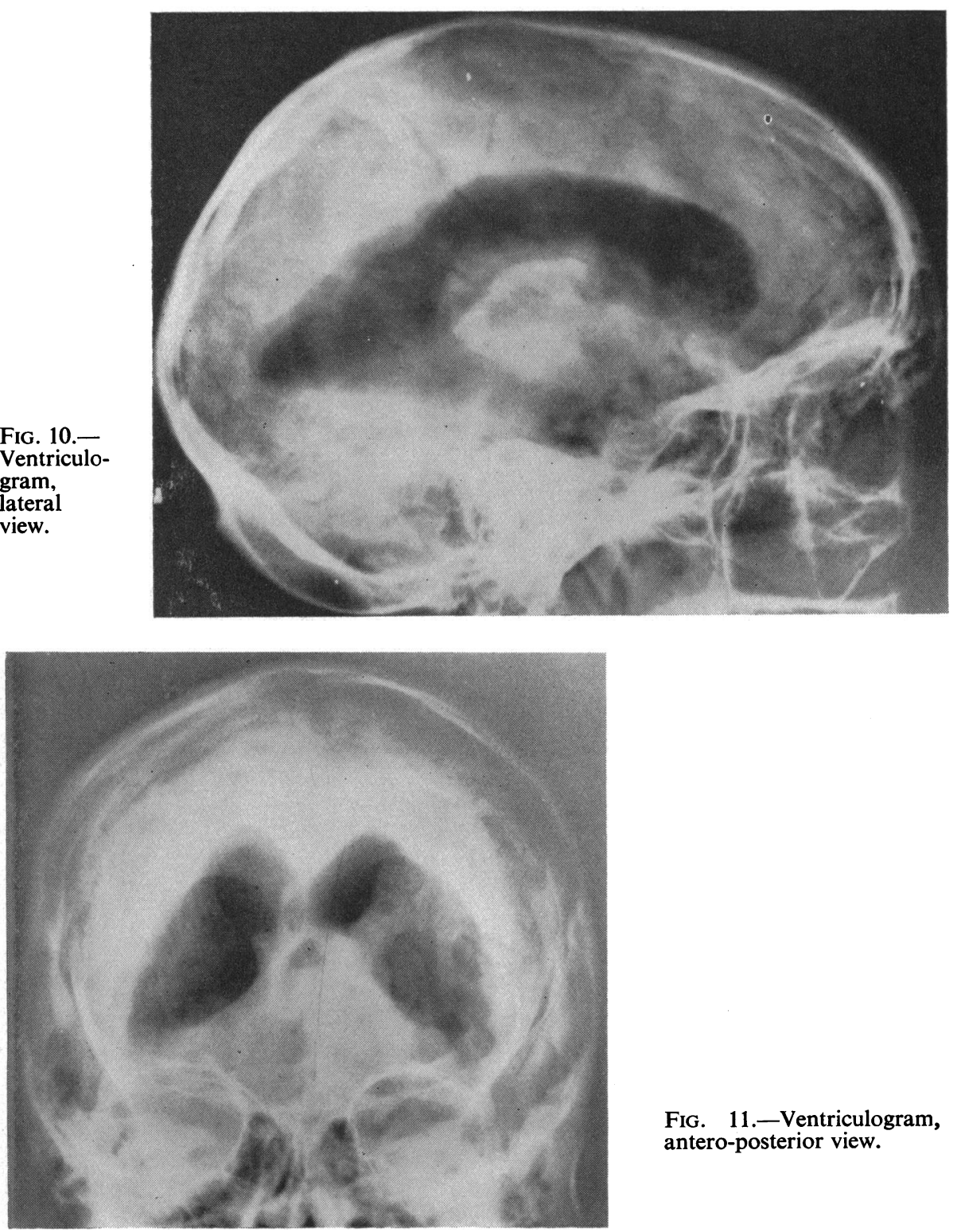

FIG. 11.-Ventriculogram, antero-posterior view. 


\section{SUMMARY}

(1) The literature concerning congenital arterio-venous aneurysm of the retina has been reviewed.

(2) Observations have been made regarding its aetiology, the appearance of the retina, and the cause of the decreased visual acuity.

(3) An additional case is fully described, with fundus drawing, encephalogram, and angiogram.

I should like to thank Dr. A. D. D. Pye, Superintendent of the Brisbane General Hospital, for permission to publish the $x$-ray films, Dr. V. E. Sampson, who originally drew my attention to the case, Dr. John Nye, for the central nervous system examination, Dr. R. Row for the $x$-ray reports, Dr. J. Hart for helpful advice, Miss L. Pegus for the fundus drawing, and the Photographic Department of the University of Queensland for the other illustrations.

\section{REFERENCES}

BiRo, I. (1951). Ophthalmologica (Basel), 121, 201.

Callander, C. L. (1920). Ann. Surg., 71, 428.

CASHELL, G. T. W. (1948). Trans. ophthal. Soc. U.K., 68, 245.

Clark, E. R. (1938). Physiol. Rev., 18, 229.

DUKE-ElDER, S. (1940). "Text-Book of Ophthalmology", vol. 3, p. 2617. Kimpton, London. MACKENZIE, I. (1953). Brain, 76, 184.

Michaelson, I. C. (1948). Trans. ophthal. Soc. U.K., 68, 137.

REESE, A. B. (1951). "Tumors of the Eye", p. 381. Hoeber, New York.

RundLes, W. Z., JNR., and FAlLS, H. F. (1951). A.M.A. Arch. Ophthal., 46, 408.

WYBURN-MASON, R. (1943). Brain, 66, 163. 
whose work and opinion were held in high regard. He became a Vice-President of the O.S.U.K., but a major affection was for the Oxford Congress founded fifty years ago by his father. Of this he was Master in the years immediately after the 1939-45 war and his delightful company there and advice on the Congress Council over the years will be remembered by many of his colleagues in Great Britain and overseas. His modest, gentle charm, his slightly diffident merry wit, and his hospitality endeared him to all who knew him.

He was fond of games, he rowed in his College boat, and with his brother, especially when in later years he lived outside Henley, he kept a keen interest in rowing all his life. But his major athletic interest which brought him international fame was in fencing, for he was twice British Amateur Foils Champion and was in the Olympic team for that weapon. His fairness, skill, and courage brought honour and many demands for service as fencer, judge, and adviser. He kept fit enough to fence regularly till the age of sixty and enjoyed the company of a wide circle of friends.

To his widow, his quiet but stalwart support, and to his daughter, his many friends extend their most real sympathy.

\section{NOAH Pines, 1888-1959}

Many people in Great Britain will be sad to hear of the death of Noah Pines on January 10, 1959. Born in Moscow he spent turbulent years as a student during the recurrent pogroms which occurred in Russia at the time. He qualified in medicine in Kiev in 1911 and when war broke out joined the Russian Army in which he achieved considerable distinction. At the time of the revolution he came to England and there took a medical degree; knowing no English he answered all his papers in Latin. Although practising ophthalmology all his life, he decided at the age of 63 to take out a special academic qualification-and succeeded. Soon after his arrival in England he became a founder member of the consultant staff of the London Jewish Hospital, and was a constant attender and frequent speaker at ophthalmological meetings. His sterling work among the casualties during the bombing of London in the second world war was officially recognized by the Order of St. John of Jerusalem. A careful clinical observer with a sound knowledge of general medicine, he will probably be best remembered for his work on vascular conditions in the fundus, particularly those associated with arteriosclerosis. He leaves a wife and three children, all of whom are doctors.

\section{KENNETH BLACK}

Mr. Kenneth Black, F.R.C.S., L.D.S., died on January 27, 1959, at the age of 79. He was formerly professor of surgery and lecturer in ophthalmology at King Edward VII Medical College, Singapore, and Surgeon to the General Hospital, Singapore.

\section{CORRIGENDA}

In the article by M. E. Cameron entitled "Congenital Arterio-Venous Aneurysms of the Retina" (Brit. J. Ophthal., 1958, 42, 655):

Page 656, line 10: for "inferior nasal artery", read "superior nasal artery".

Page 661, line 4: for "joining the left superior nasal vein and a left superior nasal artery", read "joining the right superior nasal vein and the right superior nasal artery".

Page 663, Fig. 6, Optic foramina: The labels 'left' and 'right' should be transposed. 